\title{
A TÉCNICA COMO CAPITAL E O CAPITAL hUMANO GENÉTICO'
}

OSVALDO LÓPEZ-RUIZ

\section{RESUMO}

A partir da proposta de Theodore W. Schultz, fundador da teoria do capital humano, de considerar a mudança tecnológica como uma forma de capital para os fins da análise econômica, propomos estudar as implicações lógicas de uma formulação que, na atualidade, estaria abrindo espaço para pensar o humano como uma forma de capital - e até mesmo antes de o ser humano nascer. Para isso, recorremos às reflexões de Michel Foucault feitas no seu curso Nascimento da biopolítica - recentemente publicado —, no qual chamará a atenção para o que vai designar como "o problema político da genética". Refletimos, assim, sobre as implicações sociais e econômicas da informação genética quando o objeto de estudo da economia é estendido e passa a abarcar não só certos atributos humanos, considerados agora uma forma de capital, mas também o próprio progresso técnico.

PALAVRAS-CHAVE: mudança tecnológica; capital humano; genética;

economia.

\section{ABSTRACT}

The paper discusses the logical implications of thinking the technological change as a form of capital, as suggested by T. W. Schultz for the aims of economical analysis. We argue that proposals like this, made by the founder of the human capital theory, are currently opening space to think the human as a form of capital - even before the birth of a human being. We consider what Michel Foucault called "the political problem of genetics" in his The Birth of Biopolitics, and reflect about the social and economical implications of genetic information, in particular, when the object of study of economics is extended not just to some human attributes, now considered as a form of capital, but also to technical progress itself.

KEYWORDS: technological change; human capital; genetics; economics.

[1] Este artigo faz parte do trabalho de pesquisa "Da ética protestante ao ethos empresarial: 'capital humano' e 'empreendedorismo' como valores sociais" realizado no âmbito do meu pós-doutorado no Programa de Formação de Quadros do Cebrap. Agradeço especialmente a José A. Giannotti, coordenador, e aos colegas do programa; e gostaria de agradecer também a leitura crítica e os comentários de Maria Carlotto (Cebrap), Pedro Ferreira, Anderson Santos, Rafael Alves da Silva e Diego Vincentin, do CTeMe-Unicamp.

[2] Por "razão governamental" Foucault entende os tipos de racionalidade que atuam nos procedimentos através dos quais a conduta dos
Em Naissance de la biopolitique, curso ministrado por Foucault no Collège de France em 1979 e publicado como livro na França no final de 2004, é esboçada a história do que o autor vai chamar de arte liberal de governar. Nessa história que começa, de certa forma, em meados do século XVIII, uma transformação importante é produzida: surge um novo princípio de limitação da arte de governar que não é mais extrínseco à razão governamental ${ }^{2}$, como era o direito com relação à razão de Estado. Naquela época surge a economia política, argumenta Foucault, como princípio de limitação interna da nova razão de governo. Em outras palavras, a razão governamental moderna passa a objetar o excesso de governo. Assim, o princípio que vai se impor será: não demasiado governo; é o princípio da frugalidade do governo: "A virtuous and laborious people could always be cheaply governed' in a republican system" - teria sido a afirmação feita por 
Benjamin Franklin no final do século XVIII’. Franklin é lembrado por Foucault como uma das figuras emblemáticas dessa concepção de governo frugal; concepção central, por outra parte, para o liberalismo até hoje. Dessa forma, dirá Foucault, o instrumento intelectual, a forma de cálculo e de racionalidade que fez possível a autolimitação dessa razão governamental na forma de uma autolimitação de fato, geral e intrínseca às operações próprias do governo, nãoé o direito mas a economia política - entendendo por economia política, salientará o autor, de forma ampla e prática, todos os métodos de governo suscetíveis de garantir a prosperidade de uma nação.

Contudo, argumenta Foucault, será nos Estados Unidos, mais concretamente na Universidade de Chicago, na década de 1960, onde vai se produzir uma transformação epistemológica essencial da análise neoliberal: o que vai mudaré o que tinha sido o objeto, o domínio de objetos, o campo de referência geral da análise econômica. O objeto da economia deixará de ser o estudo dos mecanismos da produção, dos mecanismos da troca e dos fatores de consumo dentro de uma estrutura social dada. O novo objeto passa a ser a análise e o estudo da forma por meio da qual os indivíduos destinam recursos raros para fins alternativos (para fins que concorrem entre si por esses recursos). A teoria do capital humano, elaborada por representantes do neoliberalismo norte-americano - ao que Foucault chama, alternativamente, de "anarco-capitalismo" ou "anarco-liberalismo" - , vai ser a responsável por toda uma mudança na forma de pensare no tipo de relacionamento entre governantes e governados. Na opinião do autor, ela representa nada menos que a reinterpretação em termos estritamente econômicos de um domínio que até então era considerado como não econômico. A economia vai tornar-se, assim, a ciência do comportamento humano. A sua tarefa será, então, a análise do comportamento humano e da racionalidade inerente a tal comportamento: "A economia", dirá Foucault, "não é mais a análise de processos, é análise da racionalidade interna, da programação estratégica da atividade dos indivíduos"4. Por isso, análises como a da teoria do capital humano permitem problematizar de uma outra forma domínios que eram, tradicionalmente, tratados pela sociologia ou pelas ciências sociais em geral: a educação, a cultura, as migrações, a saúde, a criminalidade, o divórcio etc. Com os neoliberais norteamericanos estamos, portanto, diante da generalização ilimitada da forma econômica do mercado, a qual vai se tornar princípio de inteligibilidade dos comportamentos individuais5.

[A teoria do capital humano] permite reintroduzir esses fenômenos [a educação, a criação dos filhos, a saúde etc.], não como puros e simples efeitos de mecanismos econômicos que ultrapassarão os indivíduos e que, de certaforma, os atarão a uma máquina imensa na qual elesnãoserão os amos; homens é dirigida por meio de uma administração estatal. Por outra parte, ao falar em "arte de governar" deixa claro que não está tratando da prática do governo real, mas da maneira deliberada, pensada, de governar melhor e, ao mesmo tempo, da reflexão a respeito da melhor maneira de governar (Cf. Foucault, Michel. Naissance de la biopolitique. Paris: Gallimard, 2004, pp. 4,337)

[3] Franklin teria feito essa afirmação em 1778, em carta a Charles de Weissenstein (Cf. Ibidem, pp. 30, 49 n.1,327).

[4] Ao mesmo tempo, para Foucault, a teoria do capital humano representa um avanço da análise econômica ao interior do seu próprio domínio(ibidem, p.229). Esta teoria, ao criticar a economia política clássica pela forma em que conceituou o trabalho, propõe a sua re-introdução no campo da análise econômica a partir do ponto de vista de quem trabalha (Cf. Santos, Laymert Garcia dos. "Apresentação". In: López-Ruiz, Osvaldo. Os executivos das transnancionais e o espírito do capitalismo: capital humano e empreendedorismo como valores sociais. Rio de Janeiro: Azougue, 2007, pp.16-18).

[5] “Eu acredito que temos ali não apenas a conseqüência pura e simples da projeção numa ideologia, ou numa teoria econômica, ou numa opção política, das crises atuais do capitalismo. Parece-me que o que vimos nascer ali é, por um período talvez breve ou talvez um pouco maior, algo como uma nova arte de governar, ou em todo caso uma certa renovação da arte liberal de governar" (Foucault, op. cit., p. 232). 
[6] Ibidem, p. 237. Sobre a difusão da forma "empresa" como parte constituinte de um novo ethos na sociedade contemporânea, ver LópezRuiz, Osvaldo. "Ethos empresarial: el 'capital humano' como valor social". Estudios Sociológicos, vol. XXV, n. 74, mai-ago 2007, pp.399-425.

[7] Schultz, T. W. "Capital, human".In:Sills, David L.(ed.).International encyclopedia of the social sciences. New York: Macmillan \& Free Press, 1968, pp. 278-279.

[8] Ibidem, p. 279 . ela permite analisar todos esses comportamentos em termos de empresa individual, de empresa de si mesmo com investimentos e retornos ${ }^{6}$.

\section{O CAPITAL HUMANO INATO E O CAPITAL HUMANO ADQUIRIDO}

Seo capital humanoécomposto das capacidades, habilidadesedestrezas com valor econômico e se a maior parte dessas capacidades é o produto de um investimento prévio feito pelo indivíduo, a família ou a sociedade,éverdade também que existem capacidades com as quais os seres humanos já nascem, capacidades inatas que constituem também uma forma de capital. Dito em outros termos, segundo os teóricos do capital humano, todas as capacidades úteis dos habitantes, sejam elas herdadas ou adquiridas, conformam o capital humano de uma população, embora para os efeitos do cálculo econômico sejam as adquiridas as que mais interessam. Na entrada "capital humano" da International encyclopedia of the social sciences, na sua edição de 1968 , o economista da Universidade de Chicago Theodore W. Schultz, um dos fundadores da teoria do capital humano e Prêmio Nobel de economia, vai dizer:

as capacidades herdadas de uma população são semelhantes às propriedades originárias da terra no sentido de que são "dadaspela natureza" em qualquer período de tempo significativo para a análise econômica. As variações genéticas que poderiam afetar a distribuição e nivel dessas capacidades acontecem tão vagarosamente que não têm relevância para a análise econômica. Da mesma forma parece ser verdadeiro que a distribuição das capacidades herdadas dentro de uma grande população mantém-se, aos efeitos práticos, constante ao longo do tempo, e que a distribuição dessas habilidades é aproximadamente a mesma seja o país pobre ou rico, atrasado ou moderno, sempre que a população seja numerosa7.

Como contraponto, acrescentará Schultz,

o quadro é bastante diferente no caso das capacidades adquiridas que têm valor econômico. A formação e manutenção dessas capacidades são análogas à formação e manutenção do capital humano reproduzível. Essas capacidades, evidentemente, são sujeitas à depreciação e obsolescência. Além disso, a distribuição e o nivel das capacidades adquiridas podem ser alterados significativamente durante o periodo de tempo que é relevante para a análise econômica. Historicamente, elas têm sido alteradas profundamente nos países que desenvolveram uma economia moderna ${ }^{8}$.

E, portanto, o nível de desenvolvimento dessa forma de capital constituído pelas capacidades com valor econômico que os habitantes adquirem ao longo da vida seria, então, o fator que permite explicar a 
grande diferença entre os países pobres e ricos. Isso porque a quantidade de capital humano por trabalhador varia muito entre os países, conclui o autor.

Sendo assim, e embora as capacidades inatas do homem tenham, em princípio, menor relevância para os objetivos de avaliação do crescimento econômico que motivaram as primeiras formulações da teoria do capital humano, é importante analisar alguns dos desdobramentos que esse tipo de pensamento pode ter hoje quando as mudanças tecnológicas e, em particular, os avanços da genética parecem mudar o quadro descrito por Schultz algumas décadas atrás.

\section{A QuESTÃO dO MELHORAMENTO dE CAPITAL HUMANO GENÉTICO}

Resulta interessante notar a analogia que Schultz faz entre, por um lado, as capacidades herdadas no homem e as propriedades originárias da terra e, por outro, entre as capacidades adquiridas e o capital material reproduzivel. Umas, pelo fato de serem dadas pela natureza, mudam muito vagarosamente, o que as torna pouco relevantes para a análise econômica. As outras estão sujeitas a mudanças significativas num período menor de tempo, o que as torna muito mais interessantes para esse fim aos olhos do economista norte-americano. O motor dessas mudanças, o que determina o valor econômico dessas capacidades, éo investimento (ou a falta dele e a sua conseqüente depreciação e obsolescência). Para autores como Schultz e Gary Becker (outro fundador da teoria do capital humano em Chicago, nos anos 1960, e também Prêmio Nobel de Economia, em 1992), que criticam - e devemos conceder que com razão - a adoção acrítica do legado conceitual da economia política clássica feita por muitos dos seus colegas e contemporâneos - modelos e conceitos formulados numa outra época e em resposta a um outro conjunto de problemas 9 -, é preciso reavaliar, como já mencionamos acima a respeito do trabalho, a importância e o significado econômicos de cada um dos fatores de produção para a economia moderna.

Porém, não deixa de resultar curiosa a comparação feita por Schultz entre o que para Ricardo eram "as energias produtivas da terra", "as energias originárias e indestrutíveis do solo"10, e as capacidades inatas do homem. Ambas são suscetíveis de serem tratadas de forma semelhante pela economia, segundo Schultz, pelo fato de serem dadas pela natureza e, portanto, não serem resultado de uma ação deliberada para produzi-las, como no caso do capital material ou das capacidades adquiridas. Por outro lado, também em relação aos efeitos da análise econômica, a distribuição das capacidades herdadas - sempre que dada uma grande população - podia ser assumida como
[9] Os primeiros economistas assumiram como uma de suas suposições fundamentais que o estado das artes permanecia constante. Na época de Smith ou de Ricardo, ter começado por abstrair-se das mudanças no terreno do estado das artes constituiu, sem dúvida - enfatizará Schultz -, "um golpe de mestre". Mas, nesse mundo, as mudanças ocorriam com uma lentidão glacial, concluirá Schultz: "a mutação técnica podia ser ainda tomada como um evento nãousual, pedindo apenas um breve capítulo 'Sobre a Maquinaria' [alude aqui aos Princípios de economia política e tributação, de Ricardo, de 1817]. O progresso econômico estava enraizado na divisão do trabalho e na ampliação de um acervo de capital 'homogêneo', com algum retardamento ramificado advindo dos rendimentos decrescentes em relação à terra" (Schultz, T.W. Ocapital humano: investimento em educação e pesquisa. Rio de Janeiro: Zahar Editores, 1973, p. 23).

[10] Ricardo, David.Principios de economía política y tributación. México: Fondo de Cultura Económica, 1994 [1817],pp. 51-52. 
[11] Por outro lado, estudos empíricos como o de Leibowitz concluiriam que: "A educação da mãe estava significativamente relacionada com o QI [quociente de inteligência] do filho, enquanto a do pai não, o que indicaria que os investimentos da família [home investments: principalmente, o tempo dedicado pela mãe ao cuidado dos filhos] mais do que fatores totalmente genéticos estão por trás dessa relação" (Leibowitz, Arleen. "Home investment in children", Journal of PoliticalEconomy, vol.82, n. 2-II, mar.abr. 1974, p. 129). Vale a pena lembrar que outros trabalhos dedicados ao que foi chamado de "economia da fertilidade" foram publicados em dois suplementos especiais do Journal of Political Economy, tendo Schultz como editor. Esses suplementos "New economic approach to fertility" (vol. 81, n. 2-II, 1973) e "Marriage, family human capital, and fertility" (vol. 82, n. 2-II, 1974) - trazem contribuições de Schultz e Becker como: "The value of children: an economic perspective", do primeiro, e "On the interaction between quantity and quality of children", do segundo em co-autoria com H. Gregg Lewis.

[12] Foucault, op.cit., p. 233.

[13] "Formar o capital humano, formar portanto essas espécies de competência-máquina que vão produzir a renda, enfim, que vão ser remuneradas por uma renda, isso quer dizer o quê? Isso quer dizer, claramente, fazer o que é chamado de investimentos educativos" (Ibidem, p. 235). constante tanto ao longo do tempo quanto entre os países. Como vimos, para Schultz estava claro que o que poderia afetar o nível e a distribuição dessas capacidades eram as variações genéticas, mas os efeitos destas só se manifestavam ao longo do tempo e com lentidão tal que podiam ser perfeitamente deixadas de lado ${ }^{11}$.

É importante notar como desdobramentos desta questão que ainda estavam por vir não escaparam ao olhar perspicaz, no final dos anos 1970, do professor de História dos Sistemas de Pensamento do Collège de France. Falando sobre os elementos constitutivos do capital humano no curso ditado em 1979, e já referido acima, Foucault vai argumentar:

[N] as análises, eu diria clássicas, desses neoliberais, nas análises de Schultz ou naquelas de Becker, por exemplo, é dito explicitamente que a constituição do capital humano só tem interesse, e só se torna pertinente, para os economistas, na medida em que esse capital se constitui graças à utilização de recursos raros, e de recursos raros cujo uso seria alternativo para um dado fim. Ora,é bem evidente que não temos que pagar para ter o corpo que temos, ou que não temos que pagar para ter o equipamento genético que é o nosso. Isso não custa nada. Tudo bem, isso não custa nada - enfim, precisamos ver... ${ }^{12}$.

Não havia dúvidas para Foucault de que o que interessava aos economistas de Chicago em termos de constituição do capital humano eram as capacidades adquiridas, isto é, a constituição mais ou menos voluntária de um capital humano ao longo da vida dos indivíduos. As capacidades adquiridas através do investimento são o que aumenta o valor do capital humano, diferenciando os seres humanos em função de suas habilidades e destrezas específicas, ou seja, tornando cada indivíduo possuidor de uma combinação específica de recursos, depositário não apenas de uma certa quantia, mas de uma certa composição de capital humano, que, em função dos benefícios oferecidos pelo mercado, deverá escolher onde melhor "aplicar". Certamente estava claro que era do lado dos elementos adquiridos que se colocavam todos os problemas e os novos tipos de análise que eram apresentados pelos neoliberais norte-americanos ${ }^{13}$. Em outras palavras: as capacidades adquiridas tinham interesse econômico por serem recursos raros para fins alternativos. E, como vimos, as capacidades inatas, por sua vez, eram tomadas em média como uma constante a ser desconsiderada, e isso também não escapava a Foucault. No entanto, e embora diante dos avanços da genética a questão dos elementos hereditários do capital humano não tivesse ainda emergido como problema, "alguma coisa está a caminho de nascer", alguma coisa "que poderia ser, conforme vocês prefiram, interessante ou inquietante", anunciará Foucault durante seu curso: 
A genética mostra bem que um número muito mais considerável de elementosque nósnãopodíamos imaginaratéo presente estácondicionado pelo equipamento genético que nós temos recebido de nossos ascendentes. Elepermite em particular estabelecer, para um indivíduo dado, quem ele é, as probabilidades de contrairtal ou qual tipo de doença, numa idade dada, durante um período dado da sua vida, ou de uma forma qualquer sem importar qual momento da sua vida. Dito de outraforma, um dos interesses atuais da aplicação da genética às populações humanas éa de permitir reconhecer os indivíduos em risco e o tipo de risco que os indivíduos correm ao longo de toda a sua existência. [Do momento] que podemos estabelecer quem são os indivíduos em risco, e quais são os riscos de que a união de indivíduos em risco produza um indivíduo que terá ele próprio tal e tal característica em relação ao risco do que ele será portador, podemos perfeitamente imaginar isto:que os bons equipamentos genéticos vão se tornar uma coisa rara, e que na medida em que serão uma coisa rara, isso pode perfeitamente estar, e é totalmente normal que esteja, no interior dos circuitos e do cálculo econômico, isto é, das escolhas alternativas ${ }^{14}$.

[14] Ibidem, p. 234 (grifos nossos).

Como podemos perceber, uma nova questão é colocada: o problema da raridade dos bons equipamentos genéticos e, portanto, o problema de como reproduzi-los. Porém, não basta dispor de um bom equipamento genético. É preciso achar alguém disposto também a ter um descendente que conte com um equipamento genético igual ou melhor para poder garantir o resultado. Ora, como bem destaca Foucault, produzir uma criança cujo capital humano inato seja elevado tem implicações sociais e econômicas várias. Da mesma forma que, para aumentar ao longo da vida as capacidades adquiridas da criança - seu capital humano e fonte de rendas futuras - , serão precisos investimentos consideráveis. Neste caso, serão necessários investimentos prévios para poder achar alguém com um bom material genético que queira ser "co-produtor" desse capital humano futuro. Portanto, será preciso trabalhar o suficiente e ter uma renda $e$ um status social também suficientemente elevados para poder achar um parceiro cujo capital humano seja também considerável. "Preciso salientar, no entanto", dirá Foucault, "que não estamos de forma alguma aqui beirando a zombaria: trata-se simplesmente de uma forma de pensar ou de uma espécie de problemática que atualmente está em estado de emulsão15."

No entanto, para o filósofo, a inquietação em relação à genética não deve ser pensada nos termos tradicionais do racismo. Não seria esse o problema que se coloca para a sociedade atual com os desenvolvimentos recentes da genética. Para Foucault, o que encontraria relevância política em relação à genética na atualidade é o problema do melhoramento do capital humano dos indivíduos: 
$[\mathrm{N}$ ]o momento que uma sociedade formule a si mesma o problema do melhoramento do seu capital humano em geral, não pode não apareceroproblema do controle, da filtragem, do melhoramento do capital humano dos indivíduos, em função, certamente, das uniões e das procriações que resultarão [...]. Eéportanto em termos de constituição, de crescimento, de acumulação, de melhoramento do capital humano que se coloca o problema politico da utilização da genética. Os efeitos, digamos, racistas da genética são certamente algo que épreciso temer que estálonge de estarsuperado. Porém, não me parece que seja o eixo político principal na atualidade ${ }^{16}$.

\section{A QUESTÃO dA MUDANCA TECNOLÓGICA}

Antes de encerrar sua aula de 14 de março de 1979, na qual introduziu o tema do neoliberalismo norte-americano, Foucault chamará a atenção novamente para a importância de considerar as derivações lógicas e as conseqüências políticas de um tipo de pensamento como o que estava sendo difundido nos Estados Unidos por aqueles economistas e professores em Chicago. Dirá a esse respeito:

podemos sem dúvida varrer com um gesto esse gênero de análise, ou em todo caso praticar a seu respeito a pura e simples atividade de denunciação. No entanto, acredito que isso seria ao mesmo tempo falso e perigoso. Com efeito, esse tipo de análise permite em primeiro lugar revisar em parte um certo número de fenômenos que têm sido sinalizados há um certo tempo [...] e aos quais não temos dado exatamente o status suficiente. É o problema do progresso técnico $[\ldots]]^{17}$.

Embora Foucault não explicite a referência, esse tema tinha preocupado a Schultz de forma particular, a ponto de ter dedicado o segundo capítulo do seu livro O capital humano: investimento em educação e pesquisa (Investment in human capital. The role of education and research), publicado em 1971, ao que ele vai chamar de "A questão não resolvida das mudanças tecnológicas". O problema que ali se coloca é justamente o da extensão do âmbito ao qual se aplica o conceito de tecnologia e a necessidade de incluir a mutação técnica dentro da análise econômica. Schultz vai criticar seus colegas economistas pelo uso restrito que eles vêm fazendo do conceito de tecnologia, aplicando-o apenas aos "bens de capital", isto é, a estruturas e equipamentos, deixando assim de fora da mutação técnica a terra e o homem. Ao mesmo tempo vai criticar a prática estabelecida pela economia de abordar a mutação técnica como parte de um domínio que se situa no exterior da teoria econômica. Ele vai reclamar que, embora seja óbvio que o progresso na ciência e na tecnologia tivesse se tornado uma das principais fontes do crescimento econômico, a 
economia continuava tratando a mutação técnica como se fosse um processo exógeno, que tinha a ver com decisões tomadas em outros âmbitos e por técnicos, e não por economistas. A origem desse problema é novamente atribuída à falta de revisão dos fundamentos da teoria econômica. Como já foi apontado, desde o começo os economistas abstraíram as mutações ocorridas na tecnologia, mas essa simplificação, que era perfeitamente aceitável quando a estrutura conceitual da economia política foi erigida, vai se tornar totalmente inaceitável numa época em que o crescimento econômico depende mais e mais da mutação técnica. Schultz sintetiza isso com as seguintes palavras:

A tradição teórica da economia é abstrair-se da mutação técnica; um dos pressupostos básicos da formulação clássica da teoria econômica é que a tecnologia permanece constante. Para os primeiros economistas, isto era uma engenhosa simplificação; a teoria que daí resultou era, em geral, relevante para os problemas então sob consideração. Mas, no momento em que precisamos lidar como moderno crescimento econômico, de há muito que se tornou óbvio que a suposição de que a tecnologia permanece constante é absolutamente contrária aos fatos do crescimento moderno. Não obstante, a despeito da forte prova empírica [...], a mutação técnica ainda não se transformou numa componente integral da teoria econômica. Permanece à parte, exógena, e essa marginalização é uma das principais razões por que a teoria do crescimento é de tão pouca relevância na explanação do crescimento econômico ${ }^{18}$.

[18] Schultz,op. cit., pp. 21-22.

A proposta de Schultz para sair desse impasse será pela via da integração da mutação técnica à teoria econômica, o que se conseguiria transformando, para os fins da análise econômica, a tecnologia em uma forma de capital. Mas antes de avançar nessa proposta de Schultz e analisar suas implicações, precisamos voltar à primeira crítica que ele faz a seus colegas pelo uso de um conceito de tecnologia restrito aos "bens de capital". A respeito da concepção clássica da economia ele argumentará:

Embora esta abordagem inclua instrumentos, aparelhos e equipamentos, exclui, como regra, entidades biológicas tais como animais e plantas e outros organismos que entram como itens de receita e de energia no processo de produção. [...] Enquanto todas essas entidades estão sujeitas à mutação técnica, no sentido que, em última instância, cada entidade existente pode ser substituida por uma outra com atributos técnicos diferentes, o processo de mutação técnica consiste numa porção de mutações marginais da estrutura de capital historicamente adquirida, incluindo-se a estrutura das ambiências domésticas ${ }^{19}$. 
O que Schultz vinha a propor nesse capítulo inicial do seu livro sobre capital humano - o capítulo seguinte será o central, e reproduz quase sem alterações o seu célebre artigo publicado em The American Economic Review de 1961, "Investment in human capital" — era a adoção de um conceito englobante de tecnologia que incluísse os atributos técnicos de todos os fatores e de todos os produtos. Aidéia do autor era que esse conceito levasse em conta não apenas as propriedades técnicas do tradicionalmente classificado como bens de capital, mas também as propriedades técnicas originárias da terra no sentido ricardiano. Para Schultz, as propriedades técnicas da terra são parte integral de uma dada tecnologia, e considerá-las como tal era a forma que ele via de estender a análise econômica ao âmbito das diferenças técnicas, neste caso, entre parcelas de terra. Com o mesmo critério, e seguindo o mesmo raciocínio, deviam ser consideradas as capacidades inatas dos seres humanos - no fim das contas, eram igualmente dadas pela natureza. Assim, as capacidades inatas dos homens passavam a ser integradas também dentro da economia como uma forma de capital.

Um conceito abarcante de tecnologia presumivelmente incluiria também [além das propriedades técnicas originárias do solo] as capacidades inatas do homem. Estas, também dadas pela natureza e por períodos de tempo, são também relevantes para a análise econômica, e as diferenças em tais capacidades no seio de uma população qualquer mais vasta estão sujeitas a mudanças significativas ${ }^{20}$.

Ora, certamente deve chamar a atenção do leitor que Schultz, pouco tempo depois de afirmar a quase irrelevância econômica das capacidades inatas do homem no seu artigo de 1968 para a International Encyclopedia of the Social Sciences, pareça estar afirmando o contrário em seu livro de 1971. Aqui se abre, no entanto, uma janela interessante nesse tipo de pensamento que parece nos permitir ver além das suas proposições imediatas. O que importa a Schultz e, segundo ele, deve ser motivo de interesse para a economia não são as capacidades em si mesmas - no caso, as capacidades naturais enquanto tais -, mas as mudanças que as capacidades venham a apresentar - e sejam elas mudanças originadas pela natureza ou, mais provavelmente, pelo investimento. De certa forma, é colocada em xeque aqui a categorização rígida que dividia as capacidades dos homens entre inatas e adquiridas, deslocando, assim, a ênfasee colocando-a na própria mudança.Seja como for que aconteça, será a mudança o objeto de estudo dos economistas - e, como vemos, dessa forma, o objeto da análise econômica estende-se ainda mais. Será possível, portanto, incorporar mudanças prévias ao nascimento? Mudanças no nível genético que visem alterar futuras capacidades dos homens ainda antes de eles nascerem? 
$\mathrm{Na}$ verdade, aqui tocamos num terreno no qual Schultz não avança ${ }^{21}$, e tampouco Foucault. Como vimos, a preocupação que suscita neste último uma forma de pensar como a proposta pela teoria do capital humano diante dos avanços da genética, uma certa forma de colocar os problemas em termos de destinação de recursos raros para fins alternativos, é uma preocupação centrada, claramente, nos aportes que a genética pode fazer em termos de informação, e nos efeitos sociais e econômicos que podem devir por esse "saber mais". Dito em outras palavras, o modo como Foucault chama a atenção para o problema político da genética está colocado em termos de informação e não de intervenção. Porém, há quase trinta anos desse seu assinalamento, e com quase trinta anos a mais de avanços na genética, será exagero pensar em termos de intervenção genética quando estamos tratando de um assunto como as capacidades humanas, assunto que, por outra parte, já foi colonizado pela economia? Ou, dito de outra forma, quando as capacidades humanas têm valor econômico, os investimentos para produzi-las podem estar também no plano da genética?

Sem a pretensão, nem a possibilidade, de discutir aqui o que podem e o que não podem oferecer hoje, ou num futuro próximo, a genética e a bioengenharia em termos de melhoramento das capacidade humanas com valor econômico, o que nos motiva a colocar as questões acima tem, provavelmente, uma origem semelhante ao que parece ter levado Foucault a centrar sua atenção nas análises dos neoliberais americanos. O que procuramos mostrar aqui é como as implicações lógicas de uma formulação como a da teoria do capital humano abrem espaço para pensar o humano como uma forma de capital - se entendemos por "humano" as características próprias do homem, entre elas, as capacidades, habilidades e destrezas dos seres humanos que interessam à economia - e permitem pensar o humano como uma forma de capital inclusive antes de o ser humano nascer. Dirá Schultz:

Desta forma, a idéia de mutação técnica diz respeito a atributos técnicos outros que não as propriedades originárias da terra e as inatas capacidades de trabalho. Mas o investimento para melhorar o solo e as habilidades adquiridas do homem podem alterar os atributos técnicos da terra e do homem. Daí, através do investimento, eles também estão sujeitos a mudanças técnicas ${ }^{22}$.

Naturalmente, Schultz não devia ter em mente a possibilidade de induzir mutações genéticas quando escrevia aquelas linhas há mais de três décadas. Porém, quando coloca a questão da alteração das propriedades originárias da terra e, da mesma forma e com o mesmo objetivo,
[21] Schultz não avança, mas Becker flerta. Embora não sugerindo o aprimoramento do capital humano pela via da intervenção genética, num artigo de 1973 ele afirma: "se a seleção natural genética e o comportamento racional se reforçam entre si na produção de respostas mais velozes e mais eficientes às mudanças no ambiente, talvez essa função preferencial comum tenha evoluído ao longo do tempo pela seleção natural e a escolha racional como função preferencial melhor adaptada à sociedade humana" (Michael, R. T. e Becker, G. "On the new theory of consumer behavior". Swedish J. Econ., vol. 75, n 4, dez.1973, pp.378-96). Já em 1976, Becker vai publicar "Altruism, egoism, and genetic fitness: economics and sociobiology" (Journal of Economic Literature, vol. 14, n. 3, pp. $817-826)$, no qual argumenta que tanto a economia como a sociobiologia deveriam combinar as técnicas analíticas dos economistas com as técnicas em genética populacional e entomologia da sociobiologia. Critica também os economistas por não terem incorporado os efeitos da seleção genética e, antes de propor um "modelo econômico do altruísmo", afirma: "Eu acredito que uma análise mais poderosa pode ser desenvolvida ao juntar a racionalidade individua da economia à racionalidade de grupo da sociobiologia" (p. 818)

[22] Schultz, op.cit.,p.19. 
[23] Embora o assinalamento de Foucault esteja, como argumentamos, focalizado nas implicações sociais e econômicas da informação genética, ele tem o mérito de antecipar em muitos anos, como bem lembrará Laymert Garcia dos Santos, a agenda das discussões contemporâneas sobre biogenética: "De certo modo, antecipando o que viria e, ao mesmo tempo, demarcando o terreno a partir do qual a bioengenharia do humano não só se torna possível como socialmente necessária e individualmente desejável, vale dizer, portanto uma aspiração social irreprimível, Foucault permite compreender por que numa perspectiva neoliberal 'não há alternativa' senão deixar que o mercado decida pela manipulação do genoma humano. Mais ainda: permite perceber que ele certamente o fará, apesar de todas as objeções dos humanistas e das salvaguardas que os especialistas em ética possam colocar" ("O futuro do humano". Relatório 2005 do Projeto de Pesquisa Capes, São Paulo.p. 9 [mimeo] - grifos nossos).

[24] Se houver qualquer dúvida, basta ler a introdução a "A theory of marriage" de Becker, em que afirma: "Em anos recentes, os economistas têm usado a teoria econômica mais audazmente para explicar o comportamento fora do setor do mercado monetário, e um crescente número de não-economistas têm seguido o exemplo deles. Como resultado, a discriminação racial, a fertilidade, a política, o crime, a educação, a tomada de decisão estatística, as situações adversas, a participação trabalhista, os usos do tempo de 'lazer', e outros comportamentos são muito mais bem compreendidos. De fato, a teoria econômica pode bem estar a caminho de prover um marco unificado para todo comportamento que envolva recursos raros, não-comercializáveis tanto quanto comercializáveis, não-monetários, tanto quanto monetários [...]" (Journal of Political Economy, vol. 81, n. 4, pp. 813-814 - grifo do autor).

[25] Desenvolvemos nosso argumento de que conceitos que são formulados inicialmente dentro de uma teoria econômica - como, por exemplo: "capital humano", "inovação", "empreendedorismo" etc. - passam a ser difundidos depois como valores sociais em: López-Ruiz, Os executivos das transnacionais e o espírito do capitalismo, op. cit.; “O jovem rural: afirma a possibilidade de alteração das capacidades de trabalho do homem, parece legítimo perguntar: mas qual é o limite? Há limite a uma formulação como essa quando o que está em jogo é uma fonte potencial de valor econômico? Dito de outra forma, quando ele afirma que o homem é sujeito de mudanças técnicas através do investimento, qual é a barreira que impedirá que esse investimento seja feito antes mesmo de esse homem nascer? Ou ainda, com que argumento um pai disposto a investir no aprimoramento do capital humano do seu futuro filho poderá ser dissuadido23?

Contudo, é fácil imaginar aqui a resposta que daria um Schultz ou um Becker a essas questões:essas são considerações de tipo moral, alegariam, que não dizem respeito ao tipo de trabalho científico que eles fazem nem ao objeto de estudo da ciência econômica. Mas quando a economia pretende, como ciência, estender seu objeto a toda a atividade humana, pretende ser a via de inteligibilidade para compreender a racionalidade interna da ação humana ou, em outros termos, se pretende a ciência do comportamento humano ${ }^{24}$, sobra espaço para outras instâncias como as da política ou da ética? Mais ainda, o que acontece quando os conceitos inspirados em teorias científicas se tornam valores sociais 25 ? O que acontece quando certos discursos "científicos" se tornam prescritivos - e não apenas descritivos ou explicativos - do "bom funcionamento do social"? O que acontece quando as noções de valor econômico e valor moral se aproximam demasiadamente, se entrelaçam, se tornam indistinguíveis? Assim, dispor de um alto estoque de "capital humano" é apenas economicamente bom? Desenvolver as capacidades individuais que permitirão a inserção no mundo do trabalho é apenas desejável do ponto de vista social? E, se for, podemos afirmar que é moralmente bom, que é eticamente, digamos, "responsável" - para usarmos uma formulação cara ao mundo da "ética empresarial"?

Voltemos, antes de concluir, à proposta de Schultz de integrar a mutação técnica à teoria econômica e revisemos rapidamente algumas de suas implicações. Em primeiro lugar, para que a mutação técnica deixe de ser exógena à economia, o economista sugere tratar todas as técnicas, novas e velhas, como formas de capital ou, em outras palavras, transformar a tecnologia em capital para os objetivos da análise econômica; isto é, determinar o valor econômico das entidades que contribuem para a produção, quaisquer que sejam seus atributos técnicos - o que significa, claro, trazer para o campo econômico a tarefa de avaliar a contribuição de cada atributo específico das entidades e, para isso, a necessidade de desenvolver instrumentos de medida e quantificação, na forma de técnicas e modelos econométricos, que permitam mensurar seu desempenho em termos de resultados econômicos. Em segundo lugar, estender o conceito das 
indústrias que produzem os "bens de capital" para além do que foi entendido tradicionalmente como capital. Ou seja, tratar boa parte da pesquisa científica, e também uma grande parte da educação e de outras atividades que geram capacidades com valor econômico, como "indústrias" que produzem novas formas de capital mais eficientes do que as velhas formas de capital. Em resumo, o que Schultz propõe, como é sugerido no subtítulo do seu livro, é redefinir o papel da pesquisa e da educação como "indústrias" e incluí-las estas numa análise global do processo de crescimento econômico.

Quais são as implicações dessa proposta? Principalmente, podemos resumir, uma redefinição dos conceitos no interior do domínio da economia. Schultz, no entanto, vai apontar as seguintes: 1. a técnica passa a ser pensada como capital: "a técnica não é nada mais, nada menos, do que uma unidade de capital"; 2 . enquanto "um feixe de técnicas que representam uma tecnologia é uma estrutura de capital"; 3. e "uma mutação técnica é uma alteração de uma estrutura de capital"; 4. pelo que "uma nova e mais eficiente técnica acarreta um investimento, na formação desse tipo de capital". Assim, "a longa e duradoura posição de se distinguir, tentativamente, entre técnicas e o capital vai por águas abaixo" 26 . Mas, o que é mais importante, a carga analítica recai na economia, isto é, recai a partir dali nos materiais conceituais ("investimento", "capital" etc.) com que se constrói o edifício da ciência econômica, e não, curiosamente, nos aspetos propriamente técnicos das mudanças. Isto é, dito com outras palavras palavras que dificilmente soarão estranhas para alguém que olhe o mundo hoje - : as decisões técnicas a respeito das mudanças tecnológicas passam a ser pensadas prioritariamente em termos de investimentos e retornos ao investimento.

Fica claro, portanto, que a questão do melhoramento do capital humano genético é apenas um aspecto (inclusive, ainda por vir) de uma problemática maior que se abre quando uma forma de pensar o problema econômico se expande a outras áreas e objetos aos quais é aplicada a racionalidade interna estabelecida pela própria economia. Aquestão da mutação técnica já faz parte, indubitavelmente, do corpo duro das doutrinas que explicam hoje o crescimento econômico pela via da inovação e que estimulam os investimentos em ciência e tecnologia para mudar e melhorar produtos e processos de produção. Quando conceitos como "capital humano", definidos dentro do âmbito de uma teoria científica, passam a ser difundidos como uma forma de as pessoas pensarem a respeito de suas capacidades, habilidades e destrezas, mas também como uma forma de se pensarem (e pensarem suas vidas) só a partir das capacidades com as quais elas podem mais diretamente se inserir no mundo social hoje, isto é, através do jogo do intercâmbio econômico; quando essas capacidades empreendedor e capitalista?", Marco Social, n. 8, set. 2006, pp. 18-21; "iSomos todos capitalistas? Del obrero al trabajador-investidor". Nueva Sociedad, n. 202, mar.-abr. 2006, pp. 87-97.

[26] Schultz,op. cit., 28. 
[27] Conforme propusemos em "Ethos empresarial", op. cit.

\begin{tabular}{l}
\hline $\begin{array}{l}\text { Recebido para publicação } \\
\text { em } 24 \text { de outubro de } 2007 .\end{array}$ \\
\hline NOVOS ESTUDOS \\
CEBRAP \\
80, março 2008 \\
pp. $127-139$ \\
\hline
\end{tabular}

raras se tornam por esse mesmo motivo desejáveis e, portanto, passam a orientar uma série de ações, uma série de esforços ("investimentos") dirigidos a obtê-las, a melhorá-las, a atualizá-las, a incrementá-las; quando, portanto, esses conceitos passam a ser internalizados como valores que orientam as condutas, como um ethos - ao qual podemos caracterizar chamando-o de "empresarial" 27 -; talvez, nesse momento, seja oportuno reler com maior cuidado uma das frases de Schultz citadas acima, tentando analisar seus possíveis desdobramentos quando, como agora, o que está em questão são "entidades biológicas" como os seres humanos: "Enquanto todas essas entidades estão sujeitas à mutação técnica, [...] em última instância, cada entidade existente pode ser substituída".

OSVALDO LÓPEZ-RUIZé sociólogo, doutor em Ciências Sociais, pesquisador do CTeMe (Grupo de Pesquisa em Conhecimento, Tecnologia e Mercado), do IFCH-Unicamp, e do Cebrap. 